\title{
Sensibilización y disposición al cambio en la formación de formadores: Perspectivas y retos
}

\section{Raising Awareness on Teacher Training Changes: Perspectives and Challenges}

\author{
Oscar Castro Vargas \\ División de Educación para el Trabajo \\ Centro de Investigación y Docencia en Educación \\ Universidad Nacional \\ Heredia, Costa Rica \\ oscava0874@gmail.com \\ Ileana Castillo Cedeño \\ Centro de Investigación y Docencia en Educación \\ Vicedecanato \\ Universidad Nacional \\ Heredia, Costa Rica \\ icastill@una.ac.cr
}

Recibido 15 de marzo de 2012 • Corregido 15 de octubre de 2012 • Aceptado 07 de noviembre de 2012

Resumen. Uno de los innumerables retos vinculados con los procesos formativos lo constituye la formación de formadores, sobre todo, en el marco de sociedades globales, neoliberales, donde predomina la competitividad de ofertas curriculares para la formación inicial y permanente de profesionales vinculados con la educación. El tema es preocupante y, por tanto, objeto de análisis, si se piensa en el profundo impacto en todos los ámbitos de la vida. Por ello, este ensayo reflexiona sobre la situación desde la descripción como exigencia básica de trascender en el análisis con respecto a la necesidad de que existan políticas educativas claras con respecto a la variedad y calidad de las ofertas curriculares; pero, ante todo, una sensibilización profunda de los formadores de formadores para que se visualicen como colectivo crítico y creativo desde donde puede generarse el cambio a partir de propuestas con sentido social y humano.

Palabras claves. Formación de formadores, cambio, transformación, complejidad, comunicación, papel del docente, disposición.

\footnotetext{
Es académico de la División de Educación para el Trabajo, del Centro de Investigación y Docencia en Educación de la Universidad Nacional. Posee una maestría en Psicología de Grupos, de la Universidad para la Cooperación Internacional. Es autor de varios artículos relacionados con el desarrollo humano y su potenciación.

2 Doctora en Mediación Pedagógica. Su formación inicial fue en Educación Preescolar. Máster en Psicopedagogía. Egresada de doctorado en Diseño Curricular y Evaluación Educativa de la Universidad de Valladolid, España. Especialista en didáctica de la Educación del consumidor. Ha laborado en distintos niveles del sistema educativo, desde preescolar hasta el universitario y diversas poblaciones, entre las que destacan: adolescentes de comunidades en desventaja social y adultos mayores. Actualmente, se desempeña como vicedecana del Centro de Investigación y Docencia en Educación.
} 


\begin{abstract}
One of the numerous challenges in the educational processes is teacher training, particularly in the framework of neo-liberal global societies ruled by the competitiveness of regular and continuous education programs in teacher training. It is a matter of concern and, therefore, a matter of analysis, if we consider the deep impact in all contexts. Accordingly, this paper discusses the situation from a descriptive perspective as a basic requirement to go beyond the analysis on the urgency of having clear educational policies related to the variety and quality of curricular programs; and, above all, a strong awareness from teacher trainers to see themselves as the critical creative mass from which change can be made, based on socially human proposals.
\end{abstract}

Keywords. Teacher training, change, transformation, complexity, communication, teacher role, willingness.

\title{
Formación de formadores en la complejidad
}

Un formador de formadores debe asumir la complejidad como la única manera ética de actuar en la diversidad y para esta. La realidad, como lo señala Morin (1994), no puede ser mutilada; hay que comprender la compleja trama de interrelaciones que se vinculan en los procesos formativos, entendidos como procesos de vida, de cambio y de transformación perenne.

La formación de formadores está implícita dentro de ese marco reflexivo de la complejidad que enuncia, de una u otra manera, que el formador debe ante todo tener disposición para generar propuestas de cambio plurivalentes, según las necesidades, en todas las áreas del quehacer académico universitario, de manera que impacten de forma oportuna y pertinente la realidad; involucra, por tanto, el compromiso de socializar el saber construido, buscar mecanismos de divulgación, para dejar huella y aprovechar al máximo los aprendizajes, en el entendido que todo proceso educativo se realiza en condiciones de gran complejidad, multidimensionalidad de contextos y situaciones que abren paso a lo imprevisible; de ahí la necesidad, también, de que la formación de formadores esté transversalizada por la investigación de situaciones emergentes.

En el entorno del quehacer del formador de formadores se exige un trabajo consciente, tal y como lo señalan Carr y Kemmins (1988), porque su práctica, por ser histórica, ética y política, amerita un dominio del saber y del ser, a la luz, necesariamente, de esa tan reiterada reflexión y autoreflexión.

Lo anterior conlleva otro reto: que el formador de formadores sea capaz de mantener un ejercicio sostenido de deliberación sobre sus propios procesos cognitivos (metacognición), lo que permite reelaboración y recreación de sus prácticas.

Por otra parte, exige que lo aprendido en su actuación o formación continua se refleje en sus prácticas docentes cotidianas, de ahí la importancia de la posibilidad del trabajo entre pares, reflexión no solo compartida, sino también que permite sistematizar, provocar descubrimientos sobre los implícitos y explícitos del proceso educativo por medio de esa crítica y autocrítica constructivas. 
El autoenamorase de la profesión educadora constituye un compromiso inherente del formador de formadores. Hoy se reconoce y considera que la educación es un acto de amor, solamente bajo los encantos del enamoramiento que implica el trabajo formativo se es capaz de generar disposición y emociones que propicien el cambio, esta es una premisa que debe prevalecer en todo actuar educativo.

En la medida en que el estudiantado que se está formado para ejercer la función formadora se sienta atraído y realmente identificado para asumir con criterio su función mediadora, será capaz de comprender su compromiso vital, el cual constituye no solo adaptarse al cambio, sino provocarlo intencionalmente.

(...) Los cambios acelerados tanto en el conocimiento como en las formas de vida exigen a los docentes una poderosa capacidad de anticipación y una flexibilidad psicológica excepcional (...) No se aprende a ser profesor/a de una vez por todas, de una vez para siempre. Desde la rigidez mental y actitudinal es imposible hacer frente a los retos que impone un cambio vertiginoso de la sociedad (...). (Santos, 2001, p. 151)

La crisis y el caos son componente vitales de la complejidad, por tanto, potenciadores del pensamiento complejo. Cada ser social tiene un conocimiento formado en función de una matriz de aprendizaje, la cual orienta la interacción entre la persona y su entorno; funciona, por otra parte, como descriptor de la vida, al indicar que la matriz de aprendizaje de cada sujeto se encuentra multideterminada, es decir, que surge de la interacción de diversos factores que confluyen y se relacionan de forma recíproca.

Los momentos de crisis son generadores exponenciales de desestructuración del conocimiento y saber, por tanto, representan una puerta abierta para el cambio, dado que obligan a buscar nuevas formas de mirar la realidad y aprender.

Actualmente se reconoce que los trances representan una oportunidad, son necesarios en el quehacer del ser humano: gracias a diversas crisis en el desarrollo del conocimiento, se han transformado sociedades, instituciones $y$, por ende, la vida ha evolucionado y coevolucionado, un acto de interaprendizaje permanente.

\section{De las perspectivas y los retos...}

Los procesos de autoevaluación, coevaluación, utilización de estrategias y técnicas como la observación participante, la no participante, el diario de campo, el análisis o estudio de casos, los talleres que privilegien el autoconocimiento y el reconocimiento de prácticas exitosas para el ejercicio profesional, según el entorno socioprofesional-mediatizador de todo proceso educativo-, constituyen herramientas valiosas para el desarrollo de la autonomía, la identidad profesional y la pertenencia institucional. 
Los procesos antes mencionados sugieren más que una necesidad, una oportunidad para el crecimiento personal, profesional y comunitario. Según Arroyo (2001), el desafío de la calidad de la educación consiste en producir acciones coherentes que sobrepasen el discurso de la evaluación técnica para que haya mejoramiento; aspecto que exige a las instancias formadoras: universidades entre otras, disposición al cambio, compromiso decidido y estrategias para la participación crítica y propositiva de las personas que tienen bajo su responsabilidad la compleja tarea de formar y liderar esos procesos.

Los espacios para la acción comunicativa, como lo señala Habermas (1994), se constituyen en procesos privilegiados para intercambiar ideas, experiencias, pensares, saberes y pasiones. Es una tarea de repensarse siempre tan necesaria y formadora de cara a una época de incertidumbre $y$, por lo tanto, de incontables retos, que exigen proponer actuaciones que superen el discurso, acciones que partan de la complejidad de la realidad, de la cotidianeidad en que se desarrollan los procesos formativos más allá de la racionalidad instrumental.

La acción comunicativa impulsa a la diversidad de criterios, dado que el mundo de la comunicación está conformado por las construcciones que se realizan en el plano social y personal-subjetivo de la vida. Desde este fundamento, cualquier idea puede ser consentida o situarse en el lienzo de la reflexión crítica.

La sensibilización forma parte también de un proceso comunicativo, activo, creativo, capaz de potenciar transformación actitudinal y de progreso, aspecto que promueve el sentido de satisfacción, por ende, de colaboración y de proactividad. Quiroga (1986) destaca la significatividad que tiene la comunicación; según se prolongue el proceso comunicativo habrá posibilidades de una mayor permeabilidad para internalizar y apropiarse de los cambios; ser parte activa de estos.

Los formadores de formadores, para ejercer de forma efectiva su función transformadora, necesariamente tienen que desarrollar sus habilidades emocionales, de forma que puedan, en condiciones de igualdad, ponerse en el lugar del otro o de los otros para poder interpretar y comprender sus realidades. Este elemento es una parte esencial del proceso formativo, porque permite confrontar lo que las personas desean, lo que el contexto dispone y las aspiraciones socioprofesionales según la realidad.

Buscar y promover la comunicación y el encuentro entre saberes y sentires es vital para potencializar la disposición al cambio, más allá de aspectos estructurales. La capacidad de internalizar el cambio como un reto personal constituye un dispositivo fundamental para la motivación y el autoconocimiento, elemento capital para luchar contra las inconsistencias multivariables propias de todos los sistemas educativos.

Si el formador de formadores parte de la convicción profunda con respecto a su papel mediador entre la cultura, la historia, la sociedad entre otros ámbitos; puede inmiscuirse, desde ese convencimiento, en procesos de mejora educativa auténtica, comprendiendo que la educación es un proceso de movilización de conciencia que permite actuaciones coherentes con los principios y valores que entraña la vida. 
Lo anterior implica una desburocratización mental, según Freire (2005):

(...) El poder invisible de la domesticación enajenante que alcanza una eficacia extraordinaria en lo que vengo llamando "burocratización de la mente". Un estado refinado de extrañeza, de "autosumisión" de la mente, del cuerpo consciente, de conformismo del individuo, de resignación ante situaciones consideradas fatalmente como inmutables (...). (p. 109)

$Y$ es que, precisamente, existe una tendencia a presentar la formación de formadores como un trabajo técnico y burocrático; legitimado por las funciones que se le asignan al docente dentro de las instituciones, las cuales dan poco margen para reflexionar sobre su propio actuar; procesos de praxis (reflexión-acción sobre la realidad), entorpecidos además por tiempos, infraestructura, planes y programas de estudio con visiones y discursos acordes con las modas educativas, pero con mallas curriculares cuya linealidad y exigencias dejan ver la dicotomía entre la teoría y la práctica; el abismo entre lo que se dice, lo que se hace y lo que es realmente posible hacer según la serie de condicionantes a las que se ven expuestos dentro del sistema. "Muchas veces el trabajo docente da muy poco margen para una tarea verdaderamente profesional, la cual incluye reflexión, autoevaluación, diseño/planificación para el cuidado y mejoramiento (...)" (Fourés, 2011, p. 152).

Ineludiblemente uno de los factores más relevantes para que el cambio pueda transitar constituye la indignación ante el conocimiento de las ideologías instauradas en el seno de las instituciones educativas. Sin duda la resistencia ha sido fuertemente arraigada en el imaginario que fue construido durante los procesos formativos desde la infancia, y desde una pedagogía de la indignación, desde donde se pueden visibilizar otros derroteros.

Los formadores de formadores deben luchar contra la dualidad de, por un lado, asumir posturas críticas para ejercer su función transformadora y, por el otro, trabajar con la sombra sutil de su formación inicial formal e informal en diferentes contextos de aprendizaje, donde fueron llamados a la sumisión, al control y al poder; aspectos siempre implícitos en los procesos educativos.

Desde esta perspectiva, es necesario propiciar encuentros dialógicos, de reflexión, que permitan vislumbrar rutas para la formación continua y permanente desde una pedagogía anclada en la autonomía del ser del educando, tal y como lo afirma Freire (2005).

Liberarse de los mitos y los ritos constituye un desafío para el formador de formadores y para la institución para la cual ofrece sus servicios, problema que no puede resolverse desde una o varias capacitaciones de 20, 30 o 40 horas o más, ofrecidas por un denominado experto en las materias o contenidos que se suponen deben ser consideradas relevantes en la formación.

Cabe recordar que la educación es un proceso de coparticipación de redes de apoyo entre personas e instancias formadoras a nivel formal e informal. Según Pinto (2012): 
URL: http://www.una.ac.cr/educare

La necesidad de comprender esta relación dialéctica de la intersujetividad, en que estar con los otros no es anularse como individualidad, sino que un desafío personal de colocarse como parte del mundo, que es común diverso para todos los participantes de la experiencia formativa, es todavía un rasgo que hay que valorar y profundizar, en la prácticas formativas más institucionalizadas. (p. 45)

Y, ante cualquier imposición, predomina la inversión personal, aquella que nace de la motivación interna y genuina del formador para generar espacios que faciliten la toma de consciencia y decisiones con respecto a la praxis.

\section{Consideraciones finales}

Los cambios son necesarios, al igual que las crisis de saber; pero ambos procesos están llenos de resistencias, como las actitudes psicológicas de los formadores, las estructuras organizativas dentro de los centros de docencia universitaria; como un todo dinámico, se deben empezar los procesos de sensibilización y disposición al cambio, promoviendo procesos de acción-reflexivo-comunicativa, para lo cual es necesario CREER, si se parte de esa premisa, se es capaz de atraer y propiciar encuentros que permitan ser mejores.

(...) implica una transformación radical de la manera en que el docente, cada docente, experimenta, entiende, acepta y vive su propia práctica cotidiana, lo que a la vez requiere de una profunda transformación de la práctica docente para volverla una praxis auténticamente educativa (...). (López, 2006, p. 6)

Toda transformación educativa debe estar permeada por una actitud de apertura que favorezca la construcción de nuevos posicionamientos educativos a la luz de la lectura permanente de la realidad que involucra análisis de la coyuntura sociohistórica, vertiginosamente variable, por tanto, compleja.

En el proceso de permeabilidad ante los cambios, tanto formador como institución, deben ser sensibles para mirar formas novedosas de modificar las estructuras para lograr el objetivo de educar con sentido.

La calidad de los procesos educativos se debe, en gran medida, a la singularidad y pluralidad del talento humano. Los centros educativos de formación tienen vida, cuando desde ellos se construyen propuestas basadas en el dinamismo, y la creatividad; eso exige el sentido de pertenencia de la comunidad educativa, aspecto trascendental para que los cambios se puedan palpar. 
Las experiencias de sistematización sobre desarrollo profesional y formación de formadores, particularmente en América Latina, aún son escasas, se requiere de legitimar el papel del docente como intelectual reflexivo que investiga y analiza su realidad, de acuerdo con lo señalado por Giroux (1990).

Las Universidades deben formar formadores para ejercer el ejercicio de su profesión con la calidad y la excelencia, con convencimiento y conciencia de que el conocimiento es una construcción social, pero además es necesario:

(...) examinar la constelación de intereses económicos, políticos y sociales que pueden reflejar las diferentes formas de conocimiento. Dicho con otras palabras, los modelos de currículum deben desarrollar formas de comprensión que relacionen las explicaciones de los significados sociales con parámetros societarios más amplios para que sean capaces de emitir un juicio sobres sus pretensiones de verdad. Giroux, 1990, citando a Sharp y Greene (p. 59)

Según lo anterior, es necesario amplificar el espacio de miradas, construir colectivamente un trabajo de sistematización que favorezca la reconceptualización de la formación docente a la luz de los variantes desafíos sociohistóricos.

\section{Referencias}

Arroyo, J. A. (2001). Incidencia de los indicadores en la calidad de la educación. El significado del concepto de calidad de la educación. San José, Costa Rica: EUCR.

Carrr, W. y Kemmins, S. (1988). Teoría crítica de la enseñanza: La investigación-acción en la formación del profesorado. Barcelona: Martínez Roca.

Fourés, C. I. (julio-diciembre, 2011). Reflexión docente y metacognición. Una mirada sobre la formación de formadores. Zona próxima, 14, 150-159. http://www.redalyc.org/src/inicio/ ArtPdfRed.jsp?iCve $=85320028010$

Freire, P. (2005). Pedagogía de la autonomía (3a reimp.). Buenos Aires: Siglo XXI.

Giroux, H. (1990). Los profesores como intelectuales. Hacia una pedagogía crítica del aprendizaje. Barcelona: Paidós.

Habermas, J. ( 1994). Teoría de la acción comunicativa. Racionalidad de la acción y racionalidad social. Madrid: Taurus.

López, J. (2006). Desarrollo humano y práctica docente. México: Trillas.

Morin, E. (1994). Introducción al pensamiento complejo. España: Gedisa. 
Pinto, R. (2012). Principios filosóficos y epistemológicos del ser docente. (Colección Pedagógica formación inicial de docentes centroamericanos de educación primaria o básica, n. 60). San José, Costa Rica: CEEC/SICA. Recuprado de http://www.ceducar.info/CEDUCAR/recursos/ biblioteca\%20online/Volumen\%2060/HTML/index.htm|\#/45/zoomed

Quiroga, A. P. (1986). Enfoques y perspectivas en psicología social. Organización escolar y desarrollo profesional (2a. ed.). Buenos Aires: Cinco.

Santos, M. Á. (2001). Enseñar o el oficio de aprender. Organización escolar y desarrollo profesional. Argentina: Homo Sapiens.

Cómo citar este artículo, según APA:

Castro, O. y Castillo, I. (2012). Sensibilización y disposición al cambio en la formación de formadores: Perspectivas y retos. Revista Electrónica Educare, 16 (Especial), 73-81. Consultado de http://www.revistas.una.ac.cr/index.php/EDUCARE/issue/view/418

Nota: Para citar este artículo en otros sistemas puede consultar el hipervínculo "Como citar el artículo" en la barra derecha de nuestro sitio web: http://www.revistas.una.ac.cr/index.php/ EDUCARE/index 